\title{
Futebol profissional: o mercado e as práticas de liberdade
}

CDD. 20.ed. 796.33

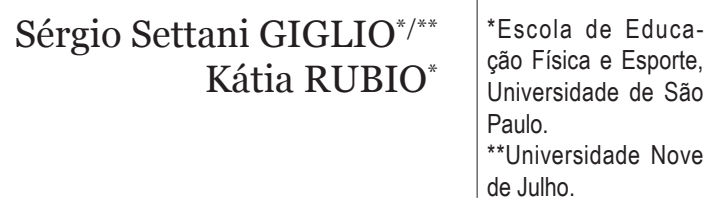

\section{Resumo}

A proposta deste artigo foi entender a relação entre a estrutura vigente do futebol profissional, que coloca os atletas em um mercado de trabalho restrito, e as práticas de liberdade como forma de posicionamento dos atletas diante da estrutura que, ao mesmo tempo, valida e controla as suas carreiras. Dessa forma, o texto foi estruturado de modo a discutir o Esporte Moderno e o controle que a Federação Internacional de Futebol (FIFA) exerce sobre futebol profissional, a mercadorização e a circulação dos jogadores brasileiros em busca dos mercados futebolísticos no exterior. Por meio de uma pesquisa bibliográfica, as práticas de liberdade foram discutidas a partir de dois episódios envolvendo os jogadores Neymar e Paulo Henrique Ganso, para entender como as suas reivindicações seguem rumos distintos. Como resultado as práticas de liberdade no futebol consistem na ação dos atletas em não se deixarem reduzir à condição de "peça" ou de "mercadoria".

Palavras-chave: Jogadores; Mercado do futebol; Futebol profissional.

\section{Introdução}

Alguns atletas do futebol atingem uma condição midiática tamanha que, em pouco tempo, são transformados em celebridades. Diferentemente dos atributos do ídolo e do herói ou do "eterno e predestinado, as celebridades vivem correndo o risco de ter outros aspectos de sua personalidade expostos como mundanos ou comuns" ${ }^{\prime 1}$ (p.156). Dessa forma, sua vida passa a ser detalhada pelos meios de comunicação como forma de revelar para os seus fãs quais são os interesses do atleta.

Atrelado à visibilidade, alguns conseguem vencer a condição de celebridade mantendo-se mais tempo em evidência. Aos atletas que permanecem por mais tempo nessa condição, o sucesso poderá ser medido por meio do apoio que recebe do público, dos programas esportivos que frequenta, das inúmeras reportagens $s^{a}$ e propagandas que participa. Essa visibilidade, em grande parte dos casos, é diretamente proporcional à assinatura de contratos milionários com o seu clube e com as agências de publicidade.

Quando o atleta de futebol consegue tirar proveito financeiro de sua carreira, muitas vezes assume uma postura acrítica em relação ao sistema esportivo do qual faz parte e como consequência não opina sobre as instâncias superiores do futebol profissional. São apenas alguns atletas que rompem o silêncio e tornam-se ativos na luta pelas práticas da liberdade no contexto futebolístico ${ }^{\mathrm{b}}$. Mas os que se posicionam de forma crítica sabem que a qualquer momento podem cair no ostracismo pelo fato do sistema estar hierarquicamente estruturado e, muitas vezes, não tolerar questionamentos. Esses atletas que optam por se posicionar criticamente querem não se tornar simplesmente uma pequena parte dessa estrutura.

Desse modo, para entender essa dinâmica atual do esporte e, em especial, do futebol brasileiro, na primeira parte do texto é feita uma discussão sobre a estruturação do Esporte Moderno e o controle que a Federação Internacional de Futebol (FIFA) exerce sobre futebol profissional, em especial, a partir da mercadorização e a circulação dos jogadores brasileiros em busca dos mercados futebolísticos no exterior.

$\mathrm{Na}$ sequência, as práticas de liberdade são discutidas a partir de dois episódios ocorridos com os jogadores Neymar e Paulo Henrique Ganso, quando atuavam pelo Santos ${ }^{c}$, com o objetivo de entender como as suas reivindicações seguem rumos distintos. Para reconstituir os episódios realizamos uma pesquisa nos jornais O Estado de S. Paulo e Folha de S. Paulo, por serem os dois principais jornais impressos que circulam na cidade de São Paulo.

Portanto, o objetivo deste artigo é entender a relação entre a estrutura vigente do futebol profissional, 
que coloca os atletas em um mercado de trabalho restrito, e as práticas de liberdade como forma de posicionamento dos atletas diante da estrutura que, ao mesmo tempo, valida e controla as suas carreiras sob o constante risco em reduzir os jogadores à condição de "peça" ou "mercadoria".

\section{Método}

A revisão de literatura foi elaborada a partir da consulta de materiais acadêmicos sobre a temática ${ }^{2}$. Associada a essa revisão foi feita uma análise documental (de maio a outubro de 2010), junto aos jornais O Estado de S. Paulo e Folha de S. Paulo, das situações ocorridas com os jogadores Neymar e Paulo Henrique Ganso. A pesquisa bibliográfica, a

\section{Resultados e discussão}

\section{A mercadorização do futebol profissional}

O Esporte Moderno surgiu no final do século XIX como produto das transformações pelas quais passava a sociedade inglesa. Fruto da Revolução Industrial estava inserido numa estrutura capitalista e, posteriormente, foi exportado para outros países ${ }^{5-8}$. Entre os esportes que eram praticados nesses primórdios do Esporte Moderno, o futebol ganhou grande número de adeptos e no Brasil, depois de algum tempo ${ }^{\mathrm{d}}$, estabeleceu-se como sendo o principal esporte.

Da forma como se estruturou, o Esporte Moderno tem como características inerentes os mesmos valores da sociedade capitalista como a necessidade de mensuração dos resultados, a competitividade e a seriedade ${ }^{9}$. Dessa forma, a qualidade e eficiência são mensuradas a partir dos resultados produzidos e os vencedores são premiados com troféus e medalhas, com prêmios simbólicos ou materiais que atestam a posição alcançada. De acordo com ArDoINO e BROHM ${ }^{7}$, essa necessidade de quantificar o desempenho será responsável pela tecnologização total dos corpos, pela regulação burocrática, pelas competições, pela espetacularização e mercadorização das práticas esportivas tratadas como mercadorias. Para sustentar toda essa estrutura fez-se necessária a criação de um sistema hierárquico que é responsável por gerir o mundo do esporte. Duas das entidades máximas dessa estrutura são o COI (Comitê Olímpico Internacional) que controla os esportes olímpicos e a FIFA (Federação Internacional de Futebol) que controla especificamente tudo o que se refere ao futebol. partir de diversas fontes, permitiu examinar o tema por novas perspectivas e estabelecer conclusões inovadoras ${ }^{3}$. Dessa forma, o método qualitativo é composto por uma amostra pequena, a partir do tratamento indutivo da hipótese e a análise dos dados feita a partir da interpretação do pesquisador ${ }^{4}$.

Por meio da sua hierarquia a FIFA possui domínio total em relação ao futebol profissional, sendo que não existe futebol profissional fora do sistema FIFA $^{10}$. Abaixo da FIFA estão as Confederaçōes dos continentes que por sua vez possuem como filiados as Confederações dos países, no caso brasileiro é a Confederação Brasileira de Futebol (CBF). Ainda nessa hierarquia aparecem as Federaçóes de futebol dos Estados e vinculadas a elas os clubes, sendo que na última etapa dessa estrutura aparecem os jogadores. Portanto, qualquer situação que aconteça em alguma dessas instâncias a FIFA pode intervir, alegando sua autoridade e competência sobre o episódio.

Diante dessa estrutura que coloca os jogadores os protagonistas do espetáculo - na base da hierarquia, $\mathrm{DAMO}^{11}$ desenvolve o argumento sobre a necessidade de entendimento dos jogadores a partir de seu duplo estatuto, o de pessoa e de mercadoria. Para compor esse cenário, é preciso recorrer a WALSH e GIULIANOT$\mathrm{TI}^{12}$ (p.13) que desenvolvem o conceito de comodificação. Esse conceito refere-se à transformação de um produto ou serviço em "commodity", isto é, em algo que pode ser comercializado. Os autores definem a comodificação como sendo "a transformação de uma coisa que possui somente valor de uso para um bem que possua valor de uso e valor troca"e.

Para MARX ${ }^{13}$, o valor de uso de algo é estabelecido pela sua utilidade, sendo determinada por aquilo que é feita a mercadoria. No caso dos jogadores, isso será estabelecido pelo uso do corpo e por meio de suas técnicas corporais se definirá quanto vale um jogador. Portanto, uma das condições de ser um 
atleta é possuir saberes dentro de seu corpo. Sob essa perspectiva, devido as rotinas de treinamento, os atletas literalmente trazem incorporado o seu valor de uso e, dessa forma, o valor de troca, que converte o objeto em mercadoria, é traduzido por meio do uso de seu corpo e do que é capaz de produzir enquanto força de trabalho. Dentro dessa dinâmica, o mercado ${ }^{f}$ e o dinheiro são fundamentais para a comodificação. Se o mercado e o dinheiro ditam as regras do que se faz, para $\mathrm{DAMO}^{10}$ a consequência disso será:

A conversão de pessoa em coisa é um processo ao qual são sujeitos todos os futebolistas, pela simples razão de que existe um mercado de compra e venda bem estruturado, com fluxos preferenciais, como é o caso dos craques brasileiros em direção à Europa e dos jogadores menos prestigiados para outras partes do mundo (p.58).

De acordo com Walsh e GiUlianottit ${ }^{12}$ (p.12), se há um objeto que pode ser comercializado podemos afirmar que o mesmo possuirá um valor de uso e um valor de troca. $\mathrm{O}$ valor de uso possui seu valor definido de forma intrínseca enquanto o valor de troca é o valor estabelecido pelo mercado e que possibilita a compra de algo.

$\mathrm{O}$ jogador que tiver a sua força de trabalho corporal reconhecida no meio futebolístico aumenta as chances de transformar seu saber corporal em maior rendimento financeiro. Como veremos adiante, existe um mercado do futebol com pouca mobilidade dos atletas para clubes de diferentes divisóes. Esse valor de uso, que atesta quanto vale cada atleta, só será materializado quando são consumidos (vendidos).

Sobre as vendas dos atletas MELANI e NEGRĀO ${ }^{14}$ ressaltam que um jogador passa a ser um objeto nas mãos de investidores quando deixa de ser responsável por vender a sua própria força de trabalho. Quando o atleta se mantém alheio a esse processo, afirmam os autores, "a força de trabalho é comprada e vendida quase que de maneira independente de seu proprietário original - leva a coisificação subjetiva [...]" (p.67) e isso faz com que o atleta assimile a sua existência como parte de uma "engrenagem" vinculada a interesses que não os seus. Esse processo que estabelece a relação "[...] mercadoria-jogador é a coisificação do ser humano-atleta" ${ }^{4}$.

No entanto, o jogador poderá ter o seu valor fixado, mas se não for negociado o valor estipulado nada vale.

Diferentemente de outras pessoas, os jogadores de futebol vendem não apenas sua força de trabalho, senão que eles próprios são comprados e vendidos, como coisas. Eles podem ser mercadorias muito apreciáveis, sendo que o preço varia, nestes casos, não apenas pela relação entre oferta e a demanda convencionais, mas por uma lógica especulativa, como no mercado de ações futuras. Robinho, Kaká e Ronaldinho são, pois, commodities futebolísticas, produzidas no Brasil e cotadas segundo as leis específicas desse mercado, que concentra na Europa os principais pregões de negócios ${ }^{10}$ (p.58).

A rigidez desse controle da FIFA que monopoliza o futebol profissional acaba por restringir os mercados para os jogadores. LEONCINI ${ }^{15}$ afirma que o sistema internacional de transferências de jogadores como sendo uma das maneiras de controlar os salários dos jogadores surgiu na Inglaterra (por volta de 1900) e depois foi incorporado pela FIFA'.

Melani e Negrão ${ }^{14}$ ressaltam que as restrições do mercado de trabalho podem colocar um atleta à margem de sua profissão, pois se estiver sem contrato, sem trabalho, sem salário e, além disso, impedido de atuar por outro clube sua força de trabalho deixa de ser mercadoria e "[...] sua relação social de produção, nesse momento, está mais perto da servidão do que do trabalho assalariado" (p.66).

Desse modo os jogadores de futebol estão limitados a apenas um mercado, qual seja, o que a FIFA estabelece e controla a partir das redes das Confederações associadas ao seu sistema ${ }^{\mathrm{h}}$. Conforme apresenta FAVERO $^{16}$, os associados da FIFA devem cumprir uma série de deveres, entre os quais destaca: "obedecer à entidade, 'seguir a cartilha', não ir contra as decisóes estatutárias (mesmo que as decisóes firam leis nacionais) e promover o futebol em sua área de atuação, de acordo com as determinações e interesses da Fifa" (p.22). Um jogador que, por algum motivo, não queira mais fazer parte desse sistema não poderá migrar para outro mercado futebolístico profissional, pelo simples fato de que existe somente um único mercado futebolístico internacional. A FIFA consegue manter esse monopólio do futebol profissional pelo fato de controlar todas as instâncias que compõe esse esporte, cabendo a ela organizar os torneios, comercializar os direitos de transmissão e cotas de patrocínio.

Os jogadores que enfrentam a estrutura sofrem com as consequências de um sistema capaz de expeli-los, afinal dificilmente algum clube aceitará ter um desafeto declarado de uma estrutura que valida a profissão de futebol. A estrutura do sistema FIFA não permite a existência de dissensões e é fechado com o firme propósito de afastar todos aqueles que ousem confrontá-lo. Isso reforça um sistema que leva o jogador a se submeter às diferentes regras, mesmo que criadas de modo a privilegiar a estrutura clubística, dificultando a organização de atletas ou grupos de atletas reivindicantes. 
Os casos de Bosman ${ }^{i}$ na Europa e de Afonsinho ${ }^{j}$ no Brasil são ilustrativos sobre o tipo de retaliação a que estão sujeitos os jogadores que afrontam a instituição futebol. Nesse sentido FlorenZano ${ }^{17}$ argumenta sobre a necessidade de se criar o jogadordisciplinar, o jogador que não cria problemas:

No futebol moderno, onde se procura fabricar o jogador-disciplinar, normalizado, tornado útil e produtivo, sobretudo dócil às práticas de poder, a rebeldia constitui-se no mal que ameaça o sonho político da comunidade pura composta pelos corpos disciplinares, expostos ao contágio de uma doença que atinge o corpo e toma de assalto a alma. A rebeldia, transformada em mais uma das figuras da loucura, requer a vigilância atenta, o controle minucioso do corpo-máquina, resguardando-o do contágio de uma doença que se expressa pelo descontrole emocional, e, nos casos-limite, como violência selvagem (p.210).

$\mathrm{O}$ que não se pode perder de vista é que as exigências de disciplinar os corpos via o esporte datam de sua criação e a convenção do Esporte Moderno. Desde o momento de sua organização e sistematização foram feitas tentativas, por meio da implementação de regras, de proibir a violência no esporte. Portanto, a ideia de disciplinar os corpos não é privilégio do futebol e tampouco do futebol atual, ela vem desde a criação do esporte, passando pela universalização das regras cujo argumento central residia na igualdade de oportunidades na competição, argumento pertinente ao espírito do liberalismo e do capitalismo. Nesse sentido ELIAS ${ }^{18}$, afirma que as atividades de lazer ao se transformarem em esporte passaram a ter regras orientadas pela lógica de "justiça"k e de igualdade de oportunidades para os participantes, tornando-se mais rígida:

As regras passaram a ser mais rigorosas, mais explícitas e mais diferenciadas. A vigilância quanto ao cumprimento das regras tornou-se mais eficiente; por isso, passou a ser menos fácil fugir às punições devidas a violações das regras. Por outras palavras, sob a forma de "desportos", os confrontos de jogos envolvendo esforços musculares atingiram um nível de ordem e de autodisciplina nunca alcançados até $\mathrm{ali}^{18}$ (p.224).

Segundo LeITE Lopes ${ }^{19}$, esse enquadramento disciplinar dos jovens em internato ocorrido nos colégios ingleses de elite ("public schools") $)^{1}$ que transformou os passatempos em esporte foi fundamental para que o esporte fosse rapidamente re-apropriado também no enquadramento disciplinar e moral dos jovens das classes populares. E essa transformação dos passatempos em esporte não foi realizada sem conflitos ou resistências, conforme afirma RUBIO ${ }^{20}$ : "Depois de muita resistência os estudantes conseguiram manter a sua tradicional autonomia em relação ao uso do tempo livre" (p.48). Segundo LeITE LOPES ${ }^{19}$, esse é um ponto que a análise de ELIAS e DuNNING ${ }^{21}$ não discute e deixa de lado os processos conflituosos da transformação dos passatempos inventados nos colégio internos ingleses em espetáculos de massa. Ao fazer isso, reforça LEITE LOPES $^{19}$, a leitura desses autores enfatiza "a linearidade desse processo evolutivo" (p.156).

Portanto, essa dimensão disciplinar do esporte, que o futebol valoriza como elemento fundamental da prática do atleta, funciona como uma via de mão dupla, pois o jogador que não se "enquadra" nessa dinâmica não poderá desfrutar do futebol profissional. Para FLORENZANO ${ }^{17}$, no futebol disciplinar a equipe é uma máquina e o "jogador é peça” dessa engrenagem, sendo que a perfeita harmonia gera o bom funcionamento dela por meio da disciplina dos jogadores. Aquele que contesta pode, na lógica estabelecida, desregular a máquina tornando-se uma "peça" indesejada que pode desagregar o grupo e como consequência final afetar o valor do produto, ou seja, quanto vale o jogador no mercado de futebol profissional.

Pelo fato de os jogadores estarem vinculados ao sistema FIFA, que pertence a uma lógica estruturada a partir da compra e venda de jogadores, a sobrevida deles nesse sistema está na capacidade em integrá-lo e validá-lo, pois só assim irão circular em busca das recompensas materiais geradas por uma carreira bem sucedida. Com isso, qualquer mercado torna-se atrativo, desde que lucrativo - principalmente na negociação.

Os dados divulgados no site da CBF revelam os destinos dos jogadores brasileiros rumo ao exterior (conforme TABELA 1). Os grandes centros do futebol europeu são apenas um detalhe entre os tantos destinos dos jogadores em busca de novas possibilidades profissionais no exterior. 
TABELA 1 - Transferências de jogadores brasileiros para o exterior ${ }^{\mathrm{m}}$.

\begin{tabular}{|c|c|c|c|c|c|c|c|c|c|}
\hline \multirow{2}{*}{\multicolumn{2}{|c|}{ País }} & & 2003 & 2004 & 2005 & 2006 & 2007 & 2008 & 2009 \\
\hline & & total & 858 & 857 & 804 & 851 & 1085 & 1176 & 1017 \\
\hline 1 & Portugal & 1170 & 141 & 132 & 138 & 142 & 227 & 209 & 181 \\
\hline 2 & Japão & 302 & 48 & 35 & 40 & 49 & 57 & 32 & 41 \\
\hline 3 & Alemanha & 288 & 56 & 30 & 20 & 20 & 44 & 58 & 60 \\
\hline 4 & Itália & 274 & 29 & 27 & 34 & 39 & 47 & 53 & 45 \\
\hline 5 & Espanha & 215 & 25 & 20 & 24 & 35 & 38 & 34 & 39 \\
\hline 6 & Paraguai & 166 & 41 & 23 & 17 & 13 & 21 & 20 & 31 \\
\hline 7 & Suécia & 157 & 15 & 21 & 9 & 20 & 19 & 46 & 27 \\
\hline 8 & Grécia & 156 & 9 & 28 & 28 & 27 & 18 & 32 & 14 \\
\hline 9 & Vietnã & 139 & 6 & 17 & 30 & 16 & 20 & 16 & 34 \\
\hline 10 & Suíça & 133 & 29 & 22 & 18 & 14 & 17 & 25 & 8 \\
\hline 11 & Bolívia & 128 & 22 & 21 & 24 & 16 & 12 & 20 & 13 \\
\hline 12 & França & 117 & 18 & 23 & 21 & 14 & 14 & 15 & 12 \\
\hline 13 & China & 115 & 17 & 13 & 5 & 15 & 27 & 23 & 15 \\
\hline 14 & Estados Unidos & 112 & 9 & 19 & 12 & 10 & 14 & 23 & 25 \\
\hline 15 & Coréia do Sul & 110 & 14 & 29 & 14 & 7 & 8 & 19 & 19 \\
\hline 16 & Emirados Árabes & 104 & 9 & 13 & 14 & 9 & 18 & 29 & 12 \\
\hline 17 & Indonésia & 101 & 17 & 26 & 13 & 15 & 21 & 6 & 3 \\
\hline 18 & Uruguai & 101 & 19 & 10 & 14 & 7 & 10 & 26 & 15 \\
\hline 19 & México & 96 & 20 & 20 & 23 & 7 & 9 & 6 & 11 \\
\hline 20 & Hong Kong & 86 & 4 & 5 & 5 & 15 & 31 & 12 & 14 \\
\hline
\end{tabular}

De 2003 a $2009^{n}$, emigraram para o exterior 6.648 atletas brasileiros, sendo que o recordista de destino dos brasileiros foi Portugal (1170 jogadores), seguido de Japão (302), Alemanha (288), Itália (274) e Espanha (215). Ao confrontar os dados das transferências dos jogadores brasileiros com relatório da Deloitte Football Money League ${ }^{\circ}$ constatamos que entre os 20 primeiros clubes com maiores receitas (venda de ingressos, direitos de TV e cotas de patrocínio, "merchandising" e outras pequenas receitas) não aparecem clubes de Portugal e do Japão. As ligas mais fortes sob essa perspectiva econômica são: Inglaterra (sete clubes), Alemanha e Itália (quatro clubes), Espanha (três clubes) e França (dois clubes).

Porém, quando verificamos os outros cinco países que entram para a lista dos 10 principais destinos dos jogadores de futebol brasileiros, temos: Paraguai (166), Suécia (157), Grécia (156), Vietnã (139) e Suíça (133). Quando se fala no êxodo dos jogadores brasileiros em busca de uma estabilidade financeira não se pode pensar somente nos grandes centros futebolísticos. Os dados revelam que existe um mercado para jogadores brasileiros fora dos grandes centros econômicos do futebol e o país que concentra as maiores receitas, a Inglaterra, não recebe muitos brasileiros e ocupa apenas o $37^{\circ}$ lugar com 51 transferências de 2003 a 2009.

Entre os 10 países de destino dos atletas, apenas quatro países $(40 \%)$ correspondem aos principais centros de futebol do mundo. Pode-se dizer que os $40 \%$ representam um número considerável de transferências de jogadores brasileiros para os grandes centros, porém, esse número pode ser rapidamente reduzido se tomarmos como grandes centros somente os clubes que estão nas principais divisões desses campeonatos. Com isso, os jogadores brasileiros estão espalhados pelos mais diversos clubes e divisões dos principais centros do futebol, já que se todos estivessem vinculados à primeira divisão teríamos um campeonato alemão, italiano espanhol com clubes compostos majoritariamente por brasileiros ${ }^{\mathrm{p}}$. Para $\mathrm{DAMO}^{22}$, a venda de jogadores brasileiros ao exterior, mesmo que seja para centros futebolísticos menores sob o ponto de vista econômico e/ou da presença de grandes clubes acontece pelo fato de existir um saber compartilhado que considera os jogadores brasileiros 
como possuidores de uma técnica particular para a prática desse esporte, mas que além disso, os jogadores brasileiros são baratos e, consequentemente, são contratados em quantidade.

Essas transferências acabam por se refletir na composição das seleções nacionais de futebol. SOARES e $\mathrm{VAZ}^{23}$ analisaram, a partir dos dados divulgados pela Revista Placar (abril/maio 2006), que na Copa de 2006 mais da metade (56\%) dos jogadores convocados pelas 32 seleçôes atuavam em clubes de outros países. Esse processo de globalização acaba por criar novas fronteiras e faz com que a FIFA como controladora do futebol profissional, queira, por meio de regras, estabelecer alguns vínculos identitários dos jogadores que representam a seleção nacional.

Hoje impera a regra que o jogador que vestir a camisa de uma seleção nacional em competições oficiais não poderá mais representar outro país. Observemos que a política da Fifa é a de resguardar a estrutura dos sentimentos nacionais por avaliar que eles são positivos na produção do negócio futebol $^{23}$ (p.495).

Existe uma dualidade nas permissões da FIFA para as transferências dos jogadores. Quando o critério é clubístico há uma regra que permite a transferência dos jogadores sem grandes restrições. Com isso, muitos atletas permanecem nos clubes por pouco tempo, estabelecendo o que RIaL ${ }^{24}$ chama de rodar, em que os vínculos são transitórios, "é apenas uma passagem, algo que se faz como um trabalho, com sacrifício, para receber a recompensa de prestigio profissional e financeira" (p.58).

Ao mesmo tempo em que a FIFA permite que o jogador possa se transferir de clube ela impede que ao ter defendido uma seleção, ele possa representar outra. O critério central dessa decisão é o vínculo identitário que acionado pela via nacionalista traz embutido, como elemento central, a ideia de amor à pátria. $\mathrm{O}$ atleta que prefere permanecer em um clube por muitos anos ${ }^{q}$, estabelecendo uma relação de identificação com a torcida, cria uma relação afetiva com o clube e os torcedores ao subverter a lógica da mercadorização, pois o jogador prefere se manter no clube em vez de ser negociado.

Cada mudança de clube, de país, de time, significa desnudar o atleta, entendido enquanto mercadoria - de sua estória, de seus afetos e de seus amores. Através da sua circulação e manipulação como mercadoria, estas dimensões perdem o seu caráter simbólico e, desta forma eles se transformam, mais uma vez, em simples mercadoria de outro clube, de outro dono. As escolhas são feitas em função da quantidade de dinheiro que está em jogo; por isso, pode-se dizer que conforme as representaçôes contidas nesses textos, gente é mercadoria e não objeto/ coisa que possui marcas, que guarda estórias etc ${ }^{25}$. O ponto central dessa dualidade gerada pelo mercado do futebol acontece pelo fato de os jogadores, a mercadoria em questão, possuírem pátria enquanto as mercadorias não as têm ${ }^{26}$. Ter uma pátria significa pertencer a algum lugar, possuir uma história, ter vínculos com algum grupo que representa a sua origem. De acordo com HoBSBAWM ${ }^{27}$, esse processo de construção da nação e do nacionalismo não foi simples. Afirma o autor:

Os Estados e regimes tinham todas as razóes para reforçar, se pudessem, o patriotismo estatal com os sentimentos e símbolos da comunidade imaginária, onde e como elas se originassem, e concentrá-los sobre si mesmos. Tal como aconteceu, o tempo em que a democratização da política tornou essencial 'educar nossos mestres', 'fazer italianos', transformar 'camponeses em franceses' e fazer com que todos se ligassem a uma bandeira e a uma nação [...]. Do mesmo modo, nada estimula melhor o nacionalismo, em ambos os lados, que um conflito internacional (p.112-3).

Os vínculos apontados por Hobsbawm para analisar a constituição da nação e da nacionalidade são essenciais para entender o futebol e as relações identitárias que são estabelecidas entre os torcedores do clube e/ou da seleção. No entanto a mercadoria, sob esse ponto de vista, não possui essas raízes sendo, portanto, livre para circular. Porém, foi somente após a lei Bosman que a estrutura do futebol foi alterada com a eliminação do limite de três jogadores estrangeiros por equipe e permitiu essa livre circulação.

A pergunta de $\mathrm{DAMO}^{11}$ permite-nos entender o que está em jogo nesse processo de globalização do futebol. Assim questiona o autor: "seriam, pois, os afetos, o último reduto da mercadorização?" (p.147).

A despedida de Ronaldo, o "Fenômeno", dos campos de futebol pode trazer indícios para tentarmos responder a pergunta de Damo. Em sua entrevista coletiva que informou oficialmente o fim da carreira e após agradecer aos clubes pelos quais jogou, aos companheiros, aos técnicos e aos demais profissionais que fizeram parte de sua carreira, assim completou:

Agradecer aos meus patrocinadores, em primeiro lugar agradecer à Ambev e à Nike que estão comigo desde que eu tenho 17 anos de idade, que acreditaram em mim e que me suportaram durante toda a minha carreira, e que com certeza continuaremos ainda juntos em outros projetos. Quero agradecer à Claro, que é meu patrocinador atual, por ter acreditado em mim 
também, mas principalmente agradecer à Hypermarcas, que bancou realmente esse projeto Corinthians. Projeto que idealizamos, eu e o presidente, num café da manhã no Rio de Janeiro, onde o Fabiano Farah, que durante nove anos foi o meu agente, discutia detalhes com o Luiz Paulo Rosenberg, que é o diretor de marketing do Corinthians.

Em seu discurso de despedida, embora muito emocionado $^{r}$, Ronaldo não se esqueceu de mencionar os patrocinadores para todo o país, já que praticamente estava em rede nacional. Dos canais abertos de São Paulo, apenas a TV Cultura e o SBT não transmitiram a coletiva enquanto Globo, Record, Bandeirantes e Rede TV! interromperam suas programações para transmitir ao vivo a despedida de Ronaldo.

Essa emoção apresentada por Ronaldo em sua despedida pode ser semelhante, conforme afirma GivlianotTi ${ }^{1}$, "[...] a uma forma de morte pública” (p.162). Morte essa que, atualmente, no caso dos atletas, acontece por volta dos 35 anos de idade. Esse fato faz com que os atletas diferenciem-se das demais profissões em que a aposentadoria também acontece e muitas vezes não é fácil de ser gestada, porém ela ocorre com uma idade mais avançada. Conforme afirma $\mathrm{DAMO}^{22}$, um jogador de futebol realiza cerca de cinco mil horas de treinamento durante 10 anos e caso o atleta seja profissional esse número aumenta ainda mais. Após esses muitos anos de investimento no próprio corpo, de dedicação integral, o atleta deverá se recolocar e se qualificar para exercer uma outra profissão, afinal, nem todos os ex-jogadores possuem espaço no mundo do futebol.

Agradecer os patrocinadores, um a um, significa que sem eles, mesmo tendo um grande domínio corporal para a prática do futebol Ronaldo não teria sido Ronaldo, o Fenômeno. Ele construiu a sua imagem de jogador diretamente vinculada ao marketing esportivo. Não foi somente pelo futebol que Ronaldo destacava-se. Essas empresas vincularam produtos, com o objetivo de aumentar as vendas, à figura de Ronaldo por meio de propagandas e por conta disso o Fenômeno tinha sua imagem divulgada constantemente na televisão, no rádio, revistas, internet etc.

Mesmo tendo saído cedo do país, sua trajetória na seleção nacional permitiu aos brasileiros a construção de uma identificação com sua capacidade de superação diante das adversidades. A saída, a realização da tarefa e o retorno, etapas salientadas por CAMPBELL ${ }^{28} \mathrm{da}$ condição de herói. Para o autor, o herói é aquele “[...] que descobriu ou realizou alguma coisa além do nível normal de realizações ou de experiência. O herói é alguém que deu a própria vida por algo maior que ele mesmo" (p.131). Se tomarmos essa condição como forma de entender a carreira, a sua saída precoce do futebol brasileiro, a conquista dos principais títulos europeus e da Copa do Mundo pela seleção brasileira e o retorno, para o Corinthians, para que o público brasileiro pudesse vê-lo em campo para eternizar a sua imagem construída por meio dessas marcas, foi uma estratégia inteligente para um jogador que, ao final de sua carreira, não tinha mais a tolerância de outrora para seguidas horas de investimentos feitas no próprio corpo.

Se o futebol globalizado mantivesse uma relação direta somente com as ações de marketing a pergunta de Damo seria respondida de uma forma. Como a continuidade da entrevista caminhou para a explicação dos motivos do término de sua carreira, Ronaldo chorou ao dizer que fracassou ao não classificar o Corinthians para a Libertadores . O choro associado à declaração de amor ao clube permite responder a pergunta do Damo da seguinte maneira: sim, no futebol globalizado e cada vez mais vinculado ao marketing ainda tem espaço para os afetos. Sem essa emoção que vincula dedicação com pertencimento à atividade que desempenhou o atleta se distanciaria dos torcedores fazendo com que o futebol fosse apenas mais uma atividade laboral. Se os jogadores podem ser comparados às mercadorias, também revelam uma diferença em relação a elas por possuírem afeto.

Após essa discussão sobre o futebol e o Esporte Moderno que culminou no controle da FIFA das questôes relativas ao futebol e na circulação dos jogadores de futebol dentro de um mercado em expansão, apresentamos na sequência do texto duas situações ocorridas com os jogadores do Santos, Neymar e Paulo Henrique Ganso como possibilidade de questionar a estrutura do futebol profissional e entender os riscos aos quais os jogadores, enquanto mercadorias, estão submetidos ao se posicionarem de modo diferente daquele que se espera de um jogador profissional.

\section{Práticas de liberdade: a contestação e a repercussão}

No primeiro jogo da final do Campeonato Paulista de 2010, o Santos venceu o Santo André por 3 a 2. Por ter feito a melhor campanha, o Santos poderia perder o segundo jogo por até um gol de diferença. $\mathrm{Na}$ segunda partida, quando o jogo estava 3 a 2 para o Santo André, o Santos com dois jogadores a menos era muito pressionado pelo adversário. Com a intenção de recompor a defesa devido às expulsões o técnico do Santos, Dorival Júnior resolveu substituir o atleta Paulo Henrique Ganso, que até aquele momento era 
o jogador que fazia o Santos permanecer com a posse de bola. Quando percebeu que seria substituído rapidamente gesticulou e recusou-se a sair de campo ${ }^{29}$.

Porém, ao dizer que iria permanecer em campo e contestar a decisão do treinador, o jogador santista subverteu a lógica estabelecida e validada por aqueles que compóem o mundo do futebol e colocou em xeque a hierarquia de um time de futebol, compartilhada pelos profissionais, especialistas e torcedores ${ }^{30}$ de que o jogador cumpre ordens e que não compete a ele contestar a decisão do técnico, cabendo-lhe somente obedecer a hierarquia estabelecida.

Só quem antevê o jogo, como os fora-de-série, teria a petulância de Ganso, que fez gestos enfáticos de recusa para o técnico ao ver que Bruno Aguiar entraria em seu lugar para segurar placar adequadamente adverso. Fosse um cabeça-de-bagre, a esta hora Ganso estaria a tirar suas tralhas do armário e já pronto para ir para o olho da rua. Pois, na relação de trabalho, quebrou a disciplina, deu um pontapé na hierarquia, ao peitar Dorival Júnior ${ }^{31}$.

Aproximadamente 20 dias depois da conquista do campeonato, o jogador Ganso ganhou novamente os noticiários esportivos. Agora, ao lado de Neymar, André e Mádson, foram punidos pelo treinador por terem chegado atrasados à concentração na véspera do jogo contra o Atlético de Goiás pelo Campeonato Brasileiro de 2010. As palavras do técnico Dorival Júnior ilustram como são estabelecidas as relaçóes entre técnico e jogadores:

Prefiro que seja assim mesmo. Essa é a minha tônica

de trabalho. O Santos já foi campeão com todos tendo um comportamento profissional. Então, assim é que deve ser. [...] O puxão de orelhas nos jogadores às vezes é necessário. Posso estar prejudicando o rendimento do time agora, mas o clube é quem sairá ganhando mais na frente ${ }^{32}$.

Pouco tempo depois da conquista do título de campeão Paulista de 2010, o jogador Ganso foi indicado pela mídia e pelos torcedores como um jogador importante para defender a seleção brasileira na Copa da África do Sul de 2010. FlORENZANO ${ }^{33}$ procura uma explicação para entender o motivo pelo qual o técnico do Brasil, Dunga, não convocou o jogador: Nesse sentido, a decisão de excluir Paulo Henrique Ganso da relação dos convocados, continha uma dimensão política não explicitada. Com efeito, a recusa em acatar a ordem do treinador para deixar o gramado, empreendida na final do Campeonato Paulista, entre Santos e Santo André, na partida realizada no Pacaembu, revestia-se de um significado incômodo para o exercício do poder à medida que expressava e resgatava a tradição de autonomia dos atletas brasileiros, exibindo em público o saber que lhes fora expropriado em benefício das comissões técnicas (p.110).

Entre as justificativas de Dunga para a sua não convocação destacou-se o fato de que o treinador da seleção brasileira tinha critérios pré-estabelecidos que envolviam, entre outras coisas, a participação anterior no período de testes. Como isso não aconteceu com Ganso e nem com Neymar, eles estavam fora da lista de convocados para a Copa de 2010 .

Se seguirmos a afirmação anterior de Florenzano poderemos dizer que o episódio de contestação de Ganso relatado acima influenciou na decisão de Dunga, mas o fato de indisciplina gerado pouco tempo depois acabava por trazer certezas ao técnico de que eram, supostamente, apenas garotos e não estavam suficientemente amadurecidos para defender o país numa Copa do Mundo. FlorenZANO ressalta como o jogador contestador passa a ser visto como um "jogador-problema":

$\mathrm{O}$ atleta que passa a se chocar [...] com os mecanismos que vão produzir este jogador como um "corpo máquina" e uma peça movida pela engrenagem do poder, é que começa a ser classificado, identificado e estigmatizado como jogador-problema. Então, quem é o jogador-problema? Ele é uma personagem que surge nesse contexto da modernização, da urgência de produzir este jogador moderno e que não se submete às exigências impostas pelo novo modelo. É o cara que não se deixa modelar fisicamente como um "corpo máquina", que recusa o comando do técnico, o qual, supostamente, não pode ser questionado. É o atleta que se desvia da norma definida para o jogador profissional. Todo um receituário: não pode beber, não pode fumar, dormir cedo, praticar sexo dentro de uma determinada regra, enfim, todo um jogo que se desenrola neste momentot.

Após a realização da Copa do Mundo de 2010, o Campeonato Brasileiro reiniciou-se em julho e já em setembro o jogador Neymar esteve envolvido em mais um problema. Ao ter um pênalti a favor do Santos contra o Atlético de Goiás, Neymar pegou a bola para realizar a cobrança. Porém, uma ordem vinda do técnico Dorival Júnior foi para outro atleta bater o pênalti. Neymar não aceitou a decisão do técnico e discutiu com o treinador antes de chutar e errar o pênalti. Dessa forma, o jogador, ao receber a informação de que não seria o cobrador do pênalti, desrespeitou os companheiros e chegou a agredir verbalmente o técnico. Horas depois, Neymar escreveu em seu Twitter: "Respeito e gosto muito do 
Dorival. É uma pessoa que tem a minha admiração. Tá tudo tranquilo. Tamo junto, professor... kkk [risos]. Gente, discussão que houve em campo é de quem quer vencer sempre. E foi em prol do grupo" ${ }^{34}$.

$\mathrm{O}$ jogador ao se manifestar via internet fornece indícios de como alguns atletas utilizam-se das novas tecnologias para se comunicar com os torcedores $^{\mathrm{u}}$. São muitos os atletas que investem em um site pessoal e/ou possuem perfis oficiais nas redes sociais. Ao não estarem em evidência apenas no momento do jogo ou nos programas esportivos, os atletas tornam-se onipresentes. Esses canais de comunicação reforçam a imagem do atleta perante os torcedores. Por isso, afirmamos anteriormente que foi necessário ao Ronaldo reconhecer as empresas que o apoiaram, pois foram elas que projetaram a imagem dele para além do futebol.

Além disso, ao postar uma mensagem, sendo uma figura pública, essa informação multiplica-se rapidamente gerando possíveis polêmicas, pois torna público o que deveria ser resolvido em âmbito privado. Mas esses canais de relacionamento virtual caminham exatamente nesse sentido da informação a qualquer momento e tudo precisa ser demonstrado, comentado e compartilhado com os supostos amigos e/ou seguidores, no caso do Twitter.

O fim dessas polêmicas aconteceu com a demissão do técnico Dorival Júnior ${ }^{35-36}$. Para entender como essa relação de poder no futebol que estabelece uma hierarquia nos clubes entre presidente, dirigentes/ conselheiros, técnicos e jogadores pode gerar o posicionamento de "status" entre as partes. Quem tem mais "status" pode recorrer ao "Você sabe com que está falando?" 37 . Nessa estrutura, é frequente perceber a relação entre o "técnico e os seus comandados"v. Porém, o desfecho desse episódio que envolveu o técnico Dorival Júnior e o jogador Neymar revela uma troca de posições quanto ao modelo hierárquico apresentado acima. Para entendermos esse fato é preciso recorrer ao pensamento de FoUCAULT ${ }^{38}$ :

$\mathrm{O}$ poder, acho eu, deve ser analisado como uma coisa que circula, ou melhor, como uma coisa que só funciona em cadeia. Jamais ele está localizado aqui ou ali, jamais está entre as mãos de alguns, jamais é apossado como uma riqueza ou um bem. $\mathrm{O}$ poder funciona. $\mathrm{O}$ poder se exerce em rede e, nessa rede, não só os indivíduos circulam, mas estão sempre em posição de ser submetidos a esse poder e também de exercê-lo. Jamais eles são o alvo inerte ou consentidor do poder, são sempre seus intermediários. Em outras palavras, o poder transita pelos indivíduos, não se aplica a eles (p.35).
Se tomado como análise o valor de troca, o de Neymar é muito maior dentro do mercado futebolístico do que o técnico Dorival Júnior, porque o atleta possui um valor de uso ${ }^{\mathrm{w}}$ maior do que o técnico, pois é a partir do uso de seu corpo que será reconhecido quanto as suas capacidades. Para o técnico ter suas capacidades evidenciadas ele necessita do desempenho dos atletas. Por isso que o poder nesse caso pode ser acessado por Neymar em detrimento do técnico, afinal, como afirmou Foucault esse poder aparece em rede e está em circulação, colocando Neymar atrelado aos interesses do presidente e dos dirigentes/conselheiros.

Se o técnico Dunga, nas palavras de FlorenzA$\mathrm{No}^{33}$, não convocou Ganso para a Copa da África de 2010 por conta de seu posicionamento em não sair de campo e Neymar pela indisciplina em que vários jogadores estavam envolvidos, o técnico Mano Menezes resolveu seguir o protocolo e estabelecer os limites da liberdade para o jogador ${ }^{\mathrm{x}}$. Qualquer que fosse a atitude do treinador da seleção brasileira em relação ao Neymar ele sofreria críticas por conta da intensa exploração do caso pela imprensa ${ }^{y}$ associada ao período próximo de convocação.

Cerca de um mês após o episódio de Neymar os fatos continuaram a ter destaque na mídia. Neymar ouviu conselhos e manifestações públicas de pessoas como Pelé ${ }^{39}$, que afirmou que também começou garoto, mas que era maduro; e de sua mãe ${ }^{40}$, afirmando as qualidades de bom moço do seu filho, além do próprio jogador se manifestar sobre o caso após 44 dias $^{\mathrm{z}}$. A fala de Pelé mostra o que se espera de um jogador de destaque: que ele dê o exemplo ${ }^{\text {aa }}$. Ao tecer comparações entre Neymar e o período que foi jogador de futebol, Pelé desconsidera as diferenças entre o que era ser um jovem no final dos anos $50 \mathrm{e}$ um jovem em 2010. Segundo DurHAM ${ }^{41}$ : “[...] toda a análise de fenômenos culturais é necessariamente análise da dinâmica cultural, isto é, do processo permanente de reorganização das representações da prática social, representações estas que são simultaneamente condição e produto desta prática" (p.231).

$\mathrm{O}$ jogador como produtor dessa cultura e agente ativo na sua dinâmica também acaba por ser influenciado por ela. Desse modo, entre as mudanças culturais, podemos destacar a influência da tecnologia nas relações pessoais. Por isso, ao comparar épocas distintas é preciso ter claro quais são as características sociais e históricas de cada período, pois a comparação entre um atleta dos anos 50 e dos dias atuais vão revelar que atualmente os jogadores estão vinculados a padrôes sociais diferentes, que existem outros processos de educação e, como 
consequência, a formação dos jogadores de futebol são estabelecidas as partir de outras bases, como por exemplo, a necessidade de possuir um empresário.

Já a fala de sua mãe reforça que por trás do jogador existe uma família, que o aconselha, que discute as melhores atitudes a serem seguidas. É exatamente essa dualidade entre a personagem que os jogadores assumem quando estão na mídia e o lado humano, muitas vezes revelado pela família, que acabam por criar toda a tensão do que é ser uma figura pública no corpo de um adolescente. A cobrança por uma condição imagética do bom moço, que deve ser um bom exemplo, também carrega consigo o valor de uso, pois será por meio dele, que o corpo do jogador poderá ser equacionado enquanto uma mercadoria e ter o seu valor estipulado. Ter problemas é contribuir para uma estagnação ou redução do valor de troca.

$\mathrm{O}$ interesse por figuras públicas que podem valer excelentes negócios ao clube fez com que o Santos mantivesse, naquele momento, em seu elenco o Neymar e o Ganso, mesmo sabendo que as propostas para comprá-los seriam milionárias. Quando se fala que os jogadores brasileiros não sairão precocemente do país rumo ao exterior recorre-se ao discurso de que é preciso manter os jogadores mais tempo no país para se desenvolverem, mas no mundo do futebol, onde os negócios envolvem muito dinheiro, a ação da diretoria do Santos foi de alto risco. Ao tentar valorizar ainda mais a sua mercadoria, aumentando assim o valor de venda futura, o clube arrisca-se, pois ao não realizar o negócio nesse momento não possui nenhuma garantia de que os jogadores serão vendidos futuramente pelos valores que estimam.

\section{Os rumos de Neymar e Ganso}

O futebol por estar inserido na dinâmica do Esporte Moderno é controlado pela FIFA, entidade que sustenta hierarquicamente o futebol profissional por meio das Confederaçôes, clubes e jogadores que disputam os seus campeonatos.

É nesse cenário que os jogadores estão vinculados a uma dupla condição: pessoa e mercadoria ${ }^{10}$. Essa dualidade faz com que os jogadores possam ser tratados como "commodity" 12 . Esse duplo estatuto faz com que os jogadores fiquem reféns do sistema que os sustentam, pois qualquer contestação pode representar dificuldades de circulação dentro do sistema do futebol profissional.

Se as situaçôes ilustradas nos casos dos jogadores do Santos podem ser vistas como práticas de liberdade, ainda que de diferentes modos entre Ganso e Neymar, conforme explicitado ao longo do texto, é preciso entendê-las como parte integrante de um sistema futebolístico que coloca os atletas como mercadorias. Se o jogador se expõe na reivindicação de seus direitos ou pela simples manifestação de sua opinião, ele corre sérios riscos de sofrer uma rejeição no mercado de transferências. Se perderem o seu valor de mercado ou se ele for depreciado por tais atitudes, tanto o jogador quanto o clube deixarão de lucrar. Por isso, é muito difícil encontrar jogadores que se manifestam contrários a uma série de normatizações que em boa parte dos casos limitam a sua liberdade de expressão.

O ponto chave para entender as contestações de ambos os jogadores do time do Santos é acessar a forma como cada um as fez. Tanto Ganso quanto Neymar constestaram a hierarquia do futebol ao questionar em campo, publicamente, a decisão do técnico. O que os diferenciam foram os caminhos e os contextos do modo como manifestaram a discordância. Embora Ganso não tenha concordado com a atitude do técnico, ele se colocou na condição de que somente ele poderia resolver a situação adversa, colocando-se como um líder do time. Podemos identificar o ato de Ganso como uma ação de prática de liberdade inscrita no gesto político ${ }^{33} \mathrm{em}$ que nas entrelinhas afirmou para o técnico que deveria confiar nele, que ele era o herói que atende ao chamado ${ }^{28}$.

A atitude de Neymar mostrou que seu desempenho corporal no futebol permitiu a ele não estar vinculado a mesma condição dos demais jogadores. Seu caso revelou o "Você sabe com quem está falando?"37, às avessas, pois não validou a estrutura hierárquica do futebol, mas revelou a estrutura flutuante do poder ${ }^{38}$ que pode ser acessada na relação entre Neymar e o presidente e dirigentes/conselheiros. Neymar teve esse apoio, pois o seu valor de uso e de troca foram e são muito valorizados no mercado futebolístico. Caso não tivesse uma contrapartida, a associação de poder teria sido entre o técnico e o presidente e dirigentes/ conselheiros e o jogador teria que mudar de clube, pois na estrutura do futebol aqueles que contestaram algo foram eliminados ou tiveram dificuldades em conseguir algum espaço no futebol profissional.

Portanto, as práticas de liberdade, ilustradas nesse artigo por meio de fatos ocorridos com os jogadores Neymar e Paulo Henrique Ganso, consistem justamente na luta dos atletas em não se deixarem reduzir à condição de "peça" ou de "mercadoria" que estão ali para serem usadas até o limite e quando não forem mais úteis deverão ser trocadas para que a engrenagem ou o mercado não parem de atrair a atenção do público, da imprensa e dos patrocinadores. 


\section{Notas}

a. Neymar, por exemplo, foi capa da revista americana Time (4 mar. 2013) com a seguinte manchete: "O próximo Pelé Como a carreira do jogador de futebol brasileiros explica a economia do país".

b. Em 2013, um conjunto de 75 jogadores de futebol fizeram um manifesto contendo reivindicaçóes junto à CBF. Consultar: 75 jogadores dos principais clubes se unem para mudar calendário. Folha de S. Paulo. 24 set. 2013; Esportes:D1; Jogadores cobram CBF por mudanças. O Estado de S. Paulo. 25 set. 2013; Esportes: A25.

c. Neymar foi contratado pelo Barcelona em junho e fez a sua estreia em julho de 2013. PH Ganso, por sua vez, foi contratado junto ao São Paulo Futebol Clube em setembro de 2012.

d. No Brasil, antes do futebol, os dois esportes mais praticados eram o turfe e o remo ${ }^{42-43}$.

e. Tradução dos autores do seguinte trecho: "[...] commodification is defined as the transformation of a thing with only use-value to a good with booth use-value and exchange-value".

f. "Mercado é o grupo de compradores reais e potenciais de um "produto". O tamanho do mercado depende do número de pessoas que apresentam necessidades, têm recursos para fazer trocas e estão dispostas a oferecer esses recursos em troca do que desejam"15 (p.40).

g. "Este sistema, surgido inicialmente na Inglaterra, era baseado na noção de registro de um jogador: apenas um jogador registrado pela FA Inglesa (Federação de Futebol Inglesa) poderia jogar futebol profissional. Contudo, este registro pode estar apenas em poder dos clubes. Se o jogador quiser mudar de clube, só poderá fazê-lo caso o clube que detém seu registro permita. Esta é a definição do que costumamos chamar aqui no Brasil de 'passe'” ${ }^{15}$ (p.49-50).

h. Confederação Sul-Americana de Futebol (CONMEBOL), Confederação de Futebol da América do Norte, Central e Caribe (CONCACAF), Confederação Africana de Futebol (CAF), Confederação Asiática de Futebol (AFC), União das Federações Europeias de Futebol (UEFA) e Confederação de Futebol da Oceania (OFC).

i. A Lei Bosman refere-se a ação que o jogador belga Jean-Marc Bosman promoveu contra o seu clube, o Liége, por não conseguir se transferir para outro clube. Após anos de trâmites o atleta recebeu o veredito favorável e, dessa forma, garantiu a livre circulação dos jogadores. Além disso, foi anulada a regra que limitava a três atletas estrangeiros de atuar por uma equipe. Para saber mais sobre o caso, consultar LeONCINI ${ }^{15}$, GiUlianotti ${ }^{1}$, e FAVERO ${ }^{16}$. A sentença do caso Bosman pode ser consultada no seguinte endereço: <http://eur-lex.europa.eu/LexUriServ/LexUriServ.do?uri=CELEX:61993J0 415:ES:HTML>. Acesso em: 9 out. 2011.

j. No final dos anos 60, Afonsinho jogava pelo Botafogo do Rio de Janeiro e considerava-se preterido pelo técnico Zagallo, sendo depois de algum tempo emprestado ao Olaria. Ao retornar ao Botafogo com um novo visual (cabelo e a barba grandes), provocou reaçôes por parte do técnico Zagallo e do diretor Xisto Toniato. Os dois quiseram que o atleta cortasse o cabelo e fizesse a barba. Por considerar uma afronta e uma invasão a sua vida pessoal, Afonsinho recuou-se a ter o visual decidido por terceiros. Com isso, prevaleceu a relação de forças entre técnico/diretoria e o jogador foi impedido de treinar. Ver FLORENZANO ${ }^{17}$ e ANDRADE ${ }^{44}$.

k. Destaque dado pelo próprio Elias em seu texto (p.224).

1. Tanto Elias e Dunning ${ }^{21}$ quanto Bourdieu ${ }^{5}$ ressaltam a importância das "public schools" na transformação dos passatempos em Esporte Moderno.

m. A tabela foi montada a partir dos dados fornecidos no site da CBF. Disponível em: <http://www2.cbf.com.br/php/ transferencias.php>. Acesso em: 7 out. 2011. Ao todo, de 2003 a 2009, os jogadores brasileiros foram para 114 países diferentes. Em seu site, a CBF, disponibiliza os dados das transferências do Brasil para o exterior a partir de 2003.

n. Os dados referentes ao ano de 2010 encontram-se em atualização no site da Confederação Brasileira de Futebol.

o. Os dados publicados em 2011 referem-se a temporada 2009/2010. Disponível em http://www.deloitte.com/assets/ Dcom-UnitedKingdom/Local\%20Assets/Documents/Industries/Sports\%20Business\%20Group/UK_SBG_DFML2011. pdf. Acesso em: 14 out. 2011.

p. Se um clube tem em média 22 jogadores no elenco, poderíamos formar cerca 13 clubes alemães somente com jogadores brasileiros, 12 clubes italianos e 10 clubes espanhóis. Evidentemente que são poucos os que estão em clubes de primeira divisão desses campeonatos.

q. Os dois casos exemplares dessa situação são os goleiros Marcos (Palmeiras) e Rogério Ceni (São Paulo). O primeiro defendeu o Palmeiras durante 20 anos (1992-2012) e o segundo atua pelo São Paulo desde 1990. No dia 7 de setembro de 2011, Rogério Ceni completou 1000 jogos pelo São Paulo.

r. O fim da carreira dos atletas e, especialmente, do futebol geralmente são dramáticas. Em sua entrevista Ronaldo afirmou: "Na quinta-feira, quando eu finalmente decidi, parece que estava na UTI. Foi a minha primeira morte" (Folha de S. Paulo. 15 fev. 2011; D2). 
s. Pela fase pré-Libertadores o Corinthians empatou com o Tolima, da Colômbia, em 0 x 0 em São Paulo no primeiro jogo e na segunda partida, na Colômbia, perdeu por 2 a 0 e ficou de fora da Libertadores de 2011. A capa do caderno de Esportes da Folha de S. Paulo, do dia 3 de fevereiro de 2011, teve a seguinte manchete: "Fim: Corinthians dá vexame na Colômbia, se despede de mais uma Libertadores e mergulha na crise". Essa manchete teve como pano de fundo uma foto de Ronaldo com a mão cobrindo o rosto (Disponível em: http://acervo.folha.com.br/fsp/2011/02/03/20/5529933). O Estado de S. Paulo do mesmo dia teve como manchete: "Sonho corintiano acaba antes de começar". A foto que ilustra a reportagem é de Ronaldo olhando para o lado e ao fundo existe um cartaz escrito "panico" [sic]. No dia seguinte, os destaques dos jornais foram sobre as atitudes de alguns torcedores. Na capa da página de Esportes da Folha de S. Paulo (Disponível em: http://acervo.folha.com.br/fsp/2011/02/04/20/5529833) a manchete foi: "Isolados: torcedores corintianos picham e apedrejam, enquanto Andres [presidente do Corinthians], Tite e Ronaldo se seguram". O Estado de S. Paulo teve como manchete: "Vandalismo na crise corintiana". Nessas reportagens, ambos os jornais mostravam fotos das pichaçôes que ofendiam principalmente o jogador Ronaldo ("Ronaldo gordo sem-vergonha", "Ronaldo maldito") e o técnico Tite ("Tite técnico de merda").

t. Entrevista de José Paulo Florenzano ao site Ludopédio. 12 out. 2009. Disponível em: http://www.ludopedio.com.br/ rc/index.php/entrevistas/artigo/126. Acesso em: 30 nov. 2010.

u. Neymar 2.0 investe no 'digital total'. O Estado de S. Paulo, 30 set. 2010, p.E5. A reportagem de Valéria Zukeran dizia: "O uso de sites e outros instrumentos interativos não é novidade no mundo esportivo. A diferença está no fato de que, ao contrário de outros atletas, Neymar contará com um "planejamento digital” para aproximá-lo do público - em especial de jovens que, como ele, acessam diariamente a internet e gostam de futebol. Desta forma, o atacante poderá se tornar o que os especialistas em marketing chamam de "marca" antes mesmo de seu talento ganhar destaque em grandes centros do esporte, como Espanha, Itália e Inglaterra.

v. Esse fato pode ser evidenciado em um episódio ocorrido no Palmeiras envolvendo o técnico Luiz Felipe Scolari e o jogador Kleber. Ver as reportagens do dia 11 out. 2011: Felipão exige e diretoria decide afastar Kleber do Palmeiras. O Estado de S. Paulo, p.E5; Agressão ao volante João Vítor desencadeia briga entre Scolari e Kleber e racha o Palmeiras; atacante é afastado e deve deixar o clube, Folha de S. Paulo, p.D2.

w. Muito tempo depois dos acontecimentos, Neymar passou a receber propostas do Real Madrid e do Barcelona. A proposta do Real Madrid foi de R\$ 291 milhões (O Estado de S. Paulo. 20 set. 2011; Esportes:E1).

x. Em seu blog, o jornalista Juca Kfouri afirmou que a não convocação era o primeiro erro do técnico da seleção. Sua justificativa é que o técnico da seleção brasileira, Mano Meneses, teve atitude corporativista e que não deveria mandar recados, mas sim falar diretamente ao jogador. http://blogdojuca.uol.com.br/2010/09/o-primeoro-erro-de-mano/. Acesso em: 5 nov. 2010.

y. A não convocação de Neymar virou notícia internacional, sendo que o jornal New York Times publicou uma reportagem a seu respeito, intitulada: A Young Star at Risk of Burning Out, de autoria de Rob Hughes em que discute a rebeldia do atleta e a repercussão do caso. Disponível em http://www.nytimes.com/2010/09/29/sports/soccer/29iht-SOCCER. html. Acesso em: 7 nov. 2010.

z. "O garoto fugiu dos assuntos polêmicos, mas entrou em contradição ao falar sobre a sua mudança de comportamento. "Mudei, mas continuo sendo o Neymar de antes. Brincalhão e amigo de todos". Reportagem de Sanches Filho: Quero ter a humildade de Pelé, O Estado de S. Paulo. 22 out. 2010; Esportes:E.3.

aa. O então técnico do Atlético-GO, Renê Simões, também se manifestou sobre o episódio que envolveu Neymar. Consultar: René Simões critica Neymar: 'Estamos criando um monstro'. Disponível em: http://globoesporte.globo.com/ futebol/brasileirao-serie-a/noticia/2010/09/rene-simoes-suplica-que-eduquem-neymar-assim-virara-um-monstro.html.

\begin{abstract}
Professional football: football market and athletes freedom to voice their opinions towards the structure

The purpose of this article was to understand the connection between the current structure of professional football in which athletes are submitted to work at a restricted field, and athletes' freedom to express their opinions facing such structure, that on one hand is responsible for validate their careers, and on the other hand is also responsible for that. Therefore, the text was structured to discuss the Modern Sport and
\end{abstract}


the control that FIFA has done over professional football, the commodification of football players and the movement of Brazilian players abroad in order to find a job in the foreign market. Using a bibliographical research, athletes practices were analyzed taking into account two episodes involving the football players Neymar and Paulo Henrique Ganso, to understand some differences between their claims. The results show that, the practices of freedom in football consist of players action for reducing the status of "piece" or "good".

KEY woRDS: Players; Football market; Professional football.

\section{Referências}

1. Giulianotti R. Sociologia do futebol: dimensões históricas e socioculturais do esporte das multidões. São Paulo: Nova Alexandria; 2002.

2. Silva EL, Menezes EM. Metodologia da pesquisa e elaboração de dissertação. 4a ed. Florianópolis: UFSC; 2005.

3. Marconi MA, Lakatos EM. Técnicas de pesquisa. 4a ed. São Paulo: Atlas; 1999.

4. Thomas JR, Nelson JK. Métodos de pesquisa em atividade física. Porto Alegre: Artmed; 2002.

5. Bourdieu P. Como é possível ser esportivo? In: Bourdieu P. Questôes de sociologia. Rio de Janeiro: Marco Zero; 1983.

6. Elias N. A gênese do desporto: um problema sociológico. In: Elias N, Dunning E. A busca da excitação. Lisboa: Difel; 1992. p.187-221.

7. Ardoino J, Brohm J-M. Repères et jalons pour une intelligence critique du phénoméne sportif contemporain. In: Baillette F, Bhohm JM, editors. Critique de la modernité sportive. Paris: Les Éditions de la Passion; 1995.

8. Rubio K. O atleta e o mito do herói: o imaginário esportivo contemporâneo. São Paulo: Casa do Psicólogo; 2001.

9. Elias N. A dinâmica do desporto moderno. In: Elias N, Dunning E. A busca da excitação. Lisboa: Difel; 1992. p.299-325.

10. Damo A. O ethos capitalista e o espírito das copas. In: Gastaldo E, Guedes SL, organizadores. Naçôes em campo: Copa do Mundo e identidade nacional. Niterói: Intertexto; 2006.

11. Damo AS. Dom, amor e dinheiro no futebol de espetáculo. Rev Bras Cienc. Soc. 2008;23:139-50.

12. Walsh A, Giulianotti R. Ethics, money and sport: this sporting Mammon. In: McNamee M, Parry J. Ethics and sport. London: Routledge; 2007.

13. Marx K. O capital. 3a ed. Bauru: EDIPRO; 2008.

14. Melani, R, Negrão RF. Passe para a servidão. Discorpo. 1995;4:61-9.

15. Leoncini MP. Entendendo o negócio futebol: um estudo sobre a transformação do modelo de gestão estratégica nos clubes de futebol [tese]. São Paulo (SP): Universidade de São Paulo, Escola Politécnica; 2001.

16. Favero PM. Os donos do campo e os donos da bola: alguns aspectos da globalização do futebol [dissertação]. São Paulo (SP): Universidade de São Paulo, Faculdade de Filosofia, Letras e Ciências Humanas; 2009.

17. Florenzano JP. Afonsinho e Edmundo: a rebeldia no futebol brasileiro. São Paulo: Musa; 1998.

18. Elias N. Ensaio sobre o desporto e a violência. In: Elias N, Dunning E. A busca da excitação. Lisboa: Difel; 1992. p.223-56.

19. Leite Lopes JS. Esporte, emoção e conflito social. Mana. 1995;1:141-65.

20. Rubio K. Medalhistas olímpicos brasileiros: memórias, histórias e imaginário. São Paulo: Casa do Psicólogo/FAPESP; 2006.

21. Elias N, Dunning E. A busca da excitação. Lisboa: Difel; 1992.

22. Damo A. Do dom à profissão: formação de futebolistas no Brasil e na França. São Paulo: Aderaldo \& Rothschild; 2007.

23. Soares AJG, Vaz AF. Esporte, globalização e negócios: o Brasil dos dias de hoje. In: Priore MD, Melo VA, organizadores. História do esporte no Brasil: do Império aos dias atuais. São Paulo: Editora da UNESP; 2009.

24. Rial C. Rodar: a circulação dos jogadores de futebol”. Horizontes Antropológicos. 2008;14:21-65.

25. Pilotto FM. A fabricação dos ídolos esportivos. 23a reunião anual da ANPED; Caxambu, BR. Caxambu: ANPED; 2000.

26. Guedes SL. Mercado x pátria: a transnacionalizacao do esporte e os "europeus" do futebol brasileiro. VIII Congresso Luso-Afro-Brasileiro de Ciências Sociais; Coimbra, PT. Coimbra: Faculdade de Economia, Universidade de Coimbra, Coimbra; 2004.

27. Hobsbawm EJ. Nações e nacionalismo desde 1870: programa, mito e realidade. 2a ed. Rio de Janeiro: Paz e Terra; 1990.

28. Campbell J. O poder do mito. São Paulo: Palas Athena; 1990.

29. Ganso avisa que não sai de campo e é elogiado, Folha de S. Paulo. 3 maio 2010.

30. Toledo LH. Lógicas no futebol. São Paulo: Hucitec/Fapesp; 2002. 
31. Antero G. Ganso, o Gigante. O Estado de S. Paulo. 3 maio 2010;Esportes:E2.

32. Dorival critica garotos e diz que exige disciplina. O Estado de S. Paulo. 23 maio 2010; Esportes:E4.

33. Florenzano JP. Feras, mágicos e guerreiros: a hegemonia em jogo. Aurora. 2010;9:103-13.

34. Neymar desacata Dorival. O Estado de S. Paulo. 16 set. 2010; Esportes:E3.

35. Dorival vê proteção a Neymar e admite erro. O Estado de S. Paulo. 23 set. 2010; Esportes:E3.

36. Para Santos, Dorival Jr. forçou saída. Folha de S. Paulo. 23 set. 2010; Esportes.

37. Damatta R. Torre de babel: ensaios, crônicas, críticas, interpretaçôes e fantasias. Rio de Janeiro: Rocco; 1996.

38. Foucault M. Em defesa da sociedade: curso no Collège de France (1975-1976). 4a ed. São Paulo: Martins Fontes; 2005.

39. Críticas a Neymar. O Estado de S. Paulo. 16 out. 2010; Esportes.

40. 'Neymar é amável, não um monstro'. O Estado de S. Paulo. 26 out. 2010; Esportes.

41. Durham ER. A dinâmica da cultura. São Paulo: Cosac Naify; 2004.

42. Melo VA. Cidade sportiva: primórdios do esporte no Rio de Janeiro. Rio de Janeiro: Relume Dumará/FAPERJ; 2001. 43. Lucena RF. O esporte na cidade: aspectos do esforço civilizador brasileiro. Campinas: Autores Associados; 2001.

44. Andrade AGR. Sobre a disciplina no futebol brasileiro: uma abordagem pela Justiça Desportiva brasileira [dissertação]. Niterói(RJ): Universidade Federal Fluminense, Faculdade de Ciências Sociais; 2006.

\begin{tabular}{r|l} 
ENDEREÇO & \\
Sérgio Settani Giglio & \\
Universidade Nove de Julho & Recebido para publicação: 06/12/2011 \\
R. Guaranésia, 425 & 1a. Revisão: 27/02/2013 \\
02112-00o - São Paulo - SP - BRASIL & 2a. Revisão: 02/04/2013 \\
e-mail: Ssgiglio@usp.br & Aceito: 03/04/2013 \\
& \\
\hline
\end{tabular}

